\title{
Assessment of recreational forests by stages of recreational digression
}

\author{
Haris G. Musin ${ }^{1}$, Stanistav V. Denisov ${ }^{1}$, Ildar I. Khalilov ${ }^{2, *}$, and Rinat H. Gafiyatov ${ }^{1}$ \\ ${ }^{1}$ Kazan State Agricultural University, 420015 Kazan, Russia \\ ${ }^{2}$ Department of Rosselkhoznadzor of the Republic of Tatarstan, Kazan, Russia
}

\begin{abstract}
The paper suggests standards of maximum permissible recreational loads specified for republics and regions of the Middle Volga region, characterized by specific forest-growing conditions according to dominant rocks and age groups. The sequence of determining the stages of digression is corrected through the attendance of recreational facilities and the critical number of visitors according to the given model. Based on actual recreational accounting it is possible to model factors to adjust the recreational capacity of the forest area to critical number of visitors. The study of forest areas for mass recreation is based on the method of recreational load evaluation. The use of refined standards of maximum permissible recreational loads will allow considering the peculiarities of recreational forest exploitation for the zone of southern taiga and coniferous-broadleaf forests.
\end{abstract}

\section{Introduction}

Forest science in resource management has gained a lot of experience [1]. Today the recreational forest resources can be rapidly utilized in the sphere of business since there are already all prerequisites for rapid development of recreational activities. At the same time, the methods of assessing forest areas for mass recreation purposes are complex and cumbersome [2]. Thus, engineering and environmental surveys for the preparation of design documentation on construction, reconstruction of facilities in Moscow require assessment according to 29 indicators, each of which should receive its own ranking on a four-point scale. This can significantly complicate the assessment of territories for the development of recreational systems.

There are several directions in the methodology of recreational assessments of forest stands:

1) assessment of the territory on a landscape basis;

2) comprehensive assessment of the recreational potential of forests for attractiveness, comfort and sustainability;

3) assessment of the state of forest stands by stages of recreational digression;

4) system of economic assessment of recreational forests [3].

Regarding landscape-based assessment of recreational functions and accessibility of the area, relatively monolithic primary units of the forest landscape are combined into larger communities. The leading features of landscapes are the contrast of relief forms, mosaic and typological spectrum of forests, their aesthetic qualities, availability of water bodies and agricultural areas. With this approach in mind, the comparative assessment of recreational facilities is only possible when calculating a specific indicator of the area occupied by each category, but it will be an approximate value.

In this case, the considered categories are relative and subjective. Most importantly, such assessment does not provide information on the recreational capacity of a landscape (the number of visitors who can be in recreational conditions without compromising the biological sustainability of forest areas).

However, such an assessment is used and in percentage terms characterizes the leisure comfort in the forest. It is the basis for the complex characteristic of objects of mass recreation and its advertising.

The comprehensive assessment of the recreational potential of forests for attractiveness, comfort and sustainability is more widespread than the previous one [2]. In a labor-intensive and fractional process of assessment according to the proposed scale with the involvement of a plurality of forest-survey and ecological characteristics ( 25 indicators), the attention is drawn to sufficiently close values of obtained factors of recreational value of forest stands [4], which differ in forest-growing conditions. However, there is no basic characterizing recreational digression, i.e. the fitness of the territory for recreation by the intensity of recreational load.

Although the assessments for the first and second methods under consideration at the time of the study reflect the state of recreational potential of forests, the convergence of assessments makes $60-70$ per cent, but

\footnotetext{
* Corresponding author: halilov1985@ mail.ru
} 
for the sake of objectivity they need to be further developed.

The third direction in the methodology, according to our results [5, 6] and data of researchers [7], is the most relevant as it allows characterizing the suitability of forest recreational resources, establishing one-time and limit recreational loads on forest objects in places of mass recreation of visitors, assessing the degree of impact of recreational agents on forest territories and detecting the condition of forest stands by stages of recreational digression.

\section{Purpose of the study}

To develop the scale of recreational assessment of taxation plots taking into account the maximum permissible recreational loads for forest natural complexes.

In order to achieve this goal, the following objectives were set: to clarify the standards of maximum permissible recreational loads for the zone of southern taiga and coniferous-broadleaf forests; to justify the stepby-step principle of determining stages of recreational digression; to model factors in order to adjust the recreational capacity of the forest area to critical number of visitors based on actual recreational accounting.

The study of forest areas for mass recreation is based on the method of assessment of recreational loads described in the industry standard OST 56100-95 Methods and units of measurement of recreational loads. The recreational potential was assessed on a landscape basis and following the methodology of engineering and ecological surveys for the preparation of design documentation on construction and reconstruction of facilities in Moscow [2].

\section{Research objects}

The most visited forest territories of the republics of Mari El, Tatarstan, Samara and Nizhny Novgorod regions (water protection forests of Volga River, Kama, etc., specially protected natural areas of national parks Mari Chodra, Lower Kama, Samara Luke, popular recreational places in green areas of suburban forests of Kazan, Yoshkar-Ola, Togliatti, etc.).

\section{Results and discussion}

According to the studied direction and results of our study we recommend to use updated All-union standards for forest taxation by V.V. Zagreeva to calculate the recreational capacity and load in the territory of the republics of Marie El, Tatarstan, as well as adjacent regions [7]. Using the developed scale Values of maximum permissible recreational loads per 1 ha of forest natural complex in various forest-growing conditions for coniferous, mixed and deciduous forests, people/ha at the III stage of digression, the optimal possible number of visitors for places of mass recreation, neighborhoods, certain parts of recreational objects or objects in general without disturbance of ecological equilibrium is calculated. The obtained parameters will serve the basis for regulating the territorial accommodation of tourists, will allow determining the peculiarities of the type of recreational forest management taking into account the availability of roads, as well as classes of recreational suitability of forests.

According to the normative data, the maximum permissible recreational load per 1 hectare of the forest fund in the zone of southern taiga and coniferousbroadleaf forests is set separately for three age categories: young stand, middle-age, ripening and older tree stands. It is determined that the calculation of recreational capacity of forest stands in functional zones is carried out by soil drainage taking into account the predominant species of a certain age (Table 1) and in accordance with norms and scales for digression stages OST 56-100-95 [8] transformed for the Middle Volga region.

In defining the stages of recreational digression and drawing up a protocol for measuring a recreational load, a step-by-step differentiated principle is used, which includes the following peculiarities of using generally accepted scales and industry standards:

- Lesproekt scale shall be used to develop recreational projects [5];

- the scale of V.M. Ivonin shall be used [9] for water conservation and recreational forests of the Republic of Mari El and Tatarstan, which allows detecting the loss of protective functions by forest stands

- the classification of stages according to Lesproekt software shall be used for shrub and herbaceous phytocenoses growing on open landscapes;

- the digression stages on a recreational facility in places of mass recreation shall be defined in accordance with OST 56-100-95.

At the first stage, the transect method is used, which is intended to isolate stages of recreational digression depending on the ratio of the area melted to the mineral horizon of the surface of a ground cover to the total area of the area according to the indicators of Annex A of OST 56-100-95 (Table 1).

Table 1. Recreational digression stages by the degree of trampled down surface

\begin{tabular}{|c|c|}
\hline Stages of digression & Trampled down territory, $\%$ \\
\hline First & up to 1.0 \\
\hline Second & from 1.1 to 5.0 \\
\hline Third & from 5.1 to 10.0 \\
\hline Fourth & from 5.1 to 10.0 \\
\hline Fifth & more than 25 \\
\hline
\end{tabular}

The method is based on measuring the length of the excavated surface on computation lines uniformly covering the examined section and determining the above-mentioned index through the ratio of the length of a surface trampled down to the mineralized soil to the total length of computation lines. The minimum length of computation lines with the required error of $1 \%$ and 
confidence probability of 0.95 shall not be less than $500 \mathrm{~m}$ per hectare of the area under study.

At the second stage, after drawing up a plan-scheme of arrangement of natural complexes by stages of recreational digression, the representative areas are selected and sample areas are laid in typical taxation plots by taxation characteristic and types of forest recreation.
In accordance with OST 56-69-83, in the selected areas the forest sample areas shall be laid in kind and a card of taxation characteristic must be developed for each of them, which are supplemented by information on the type of forest recreation and the number of the recreational digression stage.

Table 2. Protocol of measuring recreational load in the test area No. 1. Brief characteristic of the test area (forest-park section of the green zone of Yoshkar-Ola)

\begin{tabular}{|l|l|}
\hline \multicolumn{1}{|c|}{ Indicator } & \multicolumn{1}{c|}{ Characteristic } \\
\hline Location & Q 11, stand 11 \\
\hline Forest type & Pine forest, cowberry grove \\
\hline Forest site type & A3 \\
\hline Stand composition & $10 \mathrm{C}$ \\
\hline Stand age, years & 85 \\
\hline Capacity class & II \\
\hline Normality & 0.7 \\
\hline Stock, $\mathrm{m}^{3}$ & 230 \\
\hline Composition, density of undergrowth & $10 \mathrm{C}, 500$ pcs ha \\
\hline Composition, density of underwood & Broom, whitebeam \\
\hline Background types and projective cover with forest live cover & Clusterberry, green moss, etc., 0.5 \\
\hline Number of recreational digression stage & third \\
\hline Test area size, ha & 0.5 \\
\hline Type of forest recreation & Forest tourism \\
\hline
\end{tabular}

Table 3. Summary list of the distribution of forest stand areas by digression stages (ha/\%) (forest-park section of the green zone of Yoshkar-Ola)

\begin{tabular}{|c|c|c|c|c|c|c|c|}
\hline $\begin{array}{c}\mathrm{n} / \mathrm{n} \\
\mathrm{Q} / \mathrm{stand}\end{array}$ & Used stand, ha & I & II & III & IV & V & Total \\
\hline $11 / 11$ & 20 & & & $20 / 57$ & & 57 \\
\hline & 10 & & & & $10 / 28.6$ & & 28.6 \\
\hline & 5 & & & & & $5 / 14.4$ & 14.4 \\
\hline Total & 35 & 0 & 0 & 57 & 28.6 & 14.4 & 100 \\
\hline
\end{tabular}

The results of the treatment are presented as Annex B protocol to OST 56-100-95 (Table 2). The obtained data for all test areas, recreational digression stages and types of forest recreation are analyzed for reporting (Table 3), for example, for the forest park area of Yoshkar-Ola.

All proposed scales identify the stages of recreational digression and provide additional information on the state of the forest landscape. In all cases, at the third and higher stages of digression the load data obtained will be the basis for sound forest and environmental measures.

Methodologically developed consistent approach to one-time and limit loads on forest objects of mass recreation allows differentiating the number of visitors by types of forest recreation $[10,11]$.
To correct and account for the presence of degraded territory, recreational capacity conversion factors are used by digression stages according to OST 56100-95 and data of researchers. The indicators for stage I make 0.99 ; stage II -0.95 ; stage III -0.90 ; stage IV -0.75 ; stage $\mathrm{V}-0.5$, which is consistent with the attendance of recreational facilities and the critical number of visitors according to the given model ( $\mathrm{Y}=50.94+52.78$ $X+20.09-X^{2}$ ) [12].

As a result of the calculations, the required amount of decrease in the number of visitors due to the presence of trampled and degraded part of the territory is determined $[11,12]$. 
Table 4. Calculation of recreational capacity and recreational load (forest-park part of the green zone of Yoshkar-Ola)

\begin{tabular}{|c|c|c|c|c|c|c|c|c|c|c|}
\hline \multirow[t]{2}{*}{$\begin{array}{c}\mathrm{n} / \mathrm{n} \\
\mathrm{Q} / \mathrm{stand}\end{array}$} & \multirow[t]{2}{*}{$\begin{array}{c}\text { Used } \\
\text { stand, ha }\end{array}$} & \multirow[t]{2}{*}{$\begin{array}{l}\text { Dominant } \\
\text { species/age }\end{array}$} & \multicolumn{3}{|c|}{ Norms* } & \multicolumn{2}{|c|}{$\mathrm{RC}^{*}$ of stands } & \multirow[t]{2}{*}{$\begin{array}{l}\text { Digression } \\
\text { stages }\end{array}$} & \multicolumn{2}{|c|}{$\begin{array}{l}\mathrm{RC}^{*} \text { taking into } \\
\text { account digression } \\
\text { stages }\end{array}$} \\
\hline & & & $\begin{array}{c}\text { S, ha per } \\
1 \mathrm{CV}\end{array}$ & \begin{tabular}{|c|}
$\mathrm{SMP}^{*}$ load \\
person/ha \\
\\
\end{tabular} & $\begin{array}{c}\text { MR } \\
\text { taking } \\
\text { into } \\
\text { account S } \\
\text { and A }\end{array}$ & $\begin{array}{l}\text { SMP* } \\
\text { person }\end{array}$ & $\begin{array}{l}\text { LRC* taking } \\
\text { into account } \mathrm{S} \\
\text { and } \mathrm{A}\end{array}$ & & SMP* & LRC* \\
\hline $11 / 11$ & 20 & $\mathrm{C} / 85$ & 1.2 & 2.0 & 1.35 & 40 & 27 & 3 & 36 & 24.3 \\
\hline & 10 & & & & & 20 & 13.5 & 4 & 15 & 10.1 \\
\hline & 5 & & & & & 10 & 6.75 & 5 & 5 & 3.4 \\
\hline total & 35 & & & & & 70 & 47 & & 56 & 38 \\
\hline
\end{tabular}

Note: SMP - single maximum permissible capacity; RC - recreation capacity; LRC - limit recreation capacity taking into account the dominant species (S) and age (A); S, ha per $1 \mathrm{CV}$ - norm area per one conditional visitor, MR - marginal rate.

\section{Conclusion}

The use of refined standards of maximum permissible recreational loads will allow considering the peculiarities of recreational forest exploitation for the zone of southern taiga and coniferous-broadleaf forests.

The phased-differentiated principle of defining the stages of recreational digression is flexible, that will allow to specify the loads on the forest areas according to the specific forest growth conditions.

This methodology is justified, and the systems of forestry practices in recreational forests are tested. The methodology will provide improving of recreational properties, increasing of sustainability of forest ecosystems under recreational loads.

The main principles of the work are implemented in regulatory documents on forestry in conditions of increased recreational loads; they are presented in textbooks and monographs.

Recommendations for forest management are implemented in the forestries of the Republic of Tatarstan. The technique can also be implemented in forest management design of recreational areas.

\section{References}

1. A.A. Gursky, Principles for improving forest resources assessment, management and exploitation in Kazakhstan, $\mathrm{PhD}$ dissertation thesis (Ekaterinburg, 1977)

2. Guidelines on engineering and environmental surveys for preparation of design documentation on construction, reconstruction of facilities in Moscow (Moscow, 2008)

3. A.I. Buzykin, Possibilities of increasing forest productivity, Factors of forest productivity, 110-129 (Nauka, Siberian Branch, Novosibirsk, 1989)
4. V.A. Zakamskiy, A.A. Krylova, N.A. Vlasova, Silvicultural and recreational assessment of the sustainability of forest phytocenoses during mass recreation in the water protection and recreational forests of the Mari Trans-Volga, Forestry bulletin, 1, 17-22 (2007)

5. V.A. Zakamsky, T.A. Konyukhova, L.A. Sahbieva, Main stages of forest and recreational assessment of forest territory on the ecological routes of Mariisky Zavolzhye, Forest Bull., 1, 48-52 (2010)

6. V.V. Zagreev, V.I. Sukhikh, V.I. Shvidenko, et al., All-union standards for forest inventory (Kolos, Moscow, 1992)

7. OST 56-100-95. Industry standard. Methods and units of measurement of recreational loads on forest natural complexes (Moscow, 1995)

8. V.M. Ivonin, V.E. Avdonin, N.D. Penkovskii, Forest Recreation: Study manual for universities (NGMA, Novocherkassk, 1999)

9. V.A. Zakamsky, N.V. Andreev, Recreational Forestry, Study manual (MarSTU, Yoshkar-Ola, 2009)

10. V.A. Zakamsky, Recreational forest management. Part I. Ecological Foundations (Mari State Technical University, Yoshkar-Ola, 2012)

11. F.V. Agliullin, V.A. Zakamsky, S.A. Denisov, State and recreational capacity of coastal forests, lakes of Marie Chodra National Park (Mari State Technical University, Yoshkar-Ola, 2000)

12. V.A. Zakamsky, A.V. Kusakin, A.A. Krylova, et al., Forestry and recreational assessment of the recreational impact on forest ecosystems in places of mass recreation along the Volga River of Mari Zavolzhya (Volga - Cheboksar Hydroelectric Power Plant Dam) (Mari State Technical University, Yoshkar-Ola, 2003) 